\section{Remembrance for Prof. Antonio Cao and Prof. Renzo Galanello}

In less than one year Antonio Cao (Cagliari, May $4^{\text {th }} 1929$ - Cagliari, June 21 ${ }^{\text {st }} 2012$ ) and Renzo Galanello (Parrano, July 21 ${ }^{\text {st }} 1948$ Cagliari, May $13^{\text {th }} 2013$ ), two amongst the greatest scientists in the fields of Pediatrics, Hematology and Thalassemia, have passed away. Their deaths are an enormous loss for all of us in the Hospital for Microcitemias in Cagliari, but also for the whole Italian and International scientific community, who recognized and admired their leadership. During the funeral ceremonies held in our Hospital where both spent the greatest part of their lives, the most touching words were those pronounced by the patients who were cured by and benefited of the scrupulous medical care of our colleagues for decades from their infancy to adulthood.

From his Sardinian father, Antonio Cao learned to appreciate and love Sardinian nature and culture and from his Jewish mother of mainland Italy the importance of a strong education and the hard work behind. Antonio Cao graduated in Medicine in 1954 at the University of Cagliari and immediately started a pediatric residency in the Pediatric Clinic of the same University. In 1962 he was appointed Professor of Pediatrics at the University of Cagliari. In 1968 he left Sardinia for Perugia, where he followed his clinical mentor, the skilled pediatrician Prof. Willy Tangheroni. In 1974 he became full Professor of Pediatrics and Director of the Pediatric Clinic and the Regional Hospital for Microcitemias, an appointment that he kept until retirement. In 1992 he was named Director of the Institute for Research on Thalassemias of the National Research Council (IRTAM, CNR), recently renamed Institute of Genetic and Biomedical Research (IRGB, CNR). There, he continued to study and actively publish until the last days of his life mentoring many young scientists who became imprinted and inspired by the greatness of his scientific method. During those years, he and David Schlesinger jointly directed the ProgeNIA project, a treasure of sophisticated studies, funded by the National Institute of Aging (NIA, USA), but based in Sardinia and aimed to investigate the genetics of aging in an isolated population of Sardinia.

Antonio Cao was primarily a pediatrician; some would say The Pediatrician, because he deeply innovated the discipline in Italy absorbing the explosion of basic knowledge coming from the most advanced fields of the basic medical sciences. He was an excellent clinician and an extremely curious scientist who used to do translational medicine even before this concept became widespread. His name is tightly linked to thalassemia, especially $\beta$-thalassemia, a genetic disease that dramatically hit Sardinia, the land he was born in and loved so much. In the 70s, he established a scientific cooperation with two innovative geneticists, Michael Kaback of UCLA and Yet Wai Kan of UCSF, who helped him fighting against $\beta$-thalassemia, designing a program of population screening, genetic counseling and prenatal diagnosis that in a decade led to the substantial eradication of $\beta$-thalassemia in Sardinia.

This task was accomplished with the essential help of Renzo Galanello, a young scientist and fellow he had known and greatly appreciated during the years spent at the University of Perugia. Renzo was captured by the scientific personality of Professor Cao during his stay in Perugia and, although born and raised in Umbria, he did not hesitate to follow his mentor Antonio Cao in his way back to Sardinia, where he lived for the rest of his life, although deeply attached to his native village where he used to return every year. He was the right arm of his mentor in the program of thalassemia control in Sardinia. He defined the theoretical criteria, flow charts and practical actuation of the carrier screening for thalassemia as a prerequisite to prenatal diagnosis. The efficacy of the screening, tightly linked to the development of improved methods of prenatal diagnosis, led to the almost eradication of $\beta$-thalassemia in Sardinia, establishing a model of disease control that was exported in numerous other countries worldwide. Lately, Renzo was among the leading scientist in the clinical validation of novel oral chelators and the diagnostic assessment of cardiac iron overload by nuclear magnetic resonance.

The studies of these two pioneers gave an outstanding contribution promoting the survival, general health and quality of life of the $\beta$ thalassemia patients worldwide. They were both members of national and international scientific societies, of editorial committees of hematology journals and scientific advisors of the Thalassemia International Federation. Their careers were signed by the reception of countless honors and prizes.

The sad feelings of his friends and colleagues after their passing were best expressed by the touching commemorative words of the Thalassemia International Federation: Dear Professors, you will be greatly missed, but indeed all you have left behind as doctors and persons will never be forgotten, will remain in the books, in the literature, in our minds but very importantly in our hearts.

Paolo Moi

Biomedical Sciences and Biotechnologies, University of Cagliari, Italy E-mail:pmoi@unica.it 